\title{
Drug utilization pattern in outdoor patients of pediatric tertiary care hospital: a cross sectional study
}

\author{
Sonal M. Parekar ${ }^{1 *}$, Girish K. Maindarkar², Vishal V. Maindarkar²
}

\author{
${ }^{1}$ Department of Pharmacology, Vilasrao Deshmukh Government Institute of Medical Sciences, Latur, Maharashtra, \\ India \\ ${ }^{2}$ Department of Pediatrics, Maindarkar Pediatric Hospital, Latur, Maharashtra, India
}

Received: 14 September 2020

Accepted: 12 October 2020

\section{*Correspondence:}

Dr. Sonal M. Parekar,

Email: drsonal.vm@gmail.com

Copyright: (C) the author(s), publisher and licensee Medip Academy. This is an open-access article distributed under the terms of the Creative Commons Attribution Non-Commercial License, which permits unrestricted non-commercial use, distribution, and reproduction in any medium, provided the original work is properly cited.

\begin{abstract}
Background: Drug utilization study is essential, as safe and effective therapeutic regimen in paediatric population is challenging. Pattern of use of drugs in pediatrics vary as compared to adults, also there is limited data available. The objective of this study was to study drug utilization pattern in pediatric patients attending pediatric outpatient department of Maindarkar pediatric hospital, Latur.

Methods: A cross sectional study was carried out for a period of six months from September 2019 to February 2020, by analysing a total 1000 prescriptions of patients who had visited the OPD of Maindarkar pediatric hospital. Prescriptions were selected by simple random sampling method.

Results: In our study, out of the total of 1000 prescriptions, 244 (24.4\%) were of neonates, $556(55.6 \%)$ were of infants (1 month to 1 year) and $200(20 \%)$ were of children above 1 year. $547(54.7 \%)$ prescriptions were of male patients and $453(45.3 \%)$ were of female patients. The most frequent classes of drugs prescribed were nonsteroidal anti-inflammatory drugs $704(70.4 \%)$, followed by drugs used for respiratory disorders $655(65.5 \%)$ and supplements (60\%). Antimicrobials were prescribed in 498 (49.8\%) prescriptions. The average number of drugs per prescription was 2.45. About two third of all the prescribed drugs (74.41\%) were from national essential medicine list. Most of the prescriptions had oral drug formulation $825(82.5 \%)$ followed by inhalational $208(20.8 \%)$ followed by injectables $150(15 \%)$. All the drugs were prescribed by brand names.

Conclusions: Our study helps health-care system to understand, interpret and improve prescribing, administration, to minimize adverse events and promote rational use of medicines.
\end{abstract}

Keywords: Drug utilization, Pediatric, Cross sectional study

\section{INTRODUCTION}

World health organisation (WHO) defined drug utilization research, as the marketing, distribution, prescription and use of a drug in society, with special emphasis on the resulting medical, social and economic consequences. ${ }^{1}$ Drug utilization studies provide insight into the efficiency of drug use. The overuse, underuse or misuse of medicines results in wastage of scarce resources and widespread health hazards. ${ }^{2}$ This necessitates a periodic review of pattern of drug utilization to ensure safe and effective treatment. ${ }^{3}$

The principal aim of drug utilization research is to facilitate the rational use of drugs in populations. For the individual patient, the rational use of a drug implies the prescription of a well documented drug at an optimal dose, together with the correct information, at an affordable price. ${ }^{4}$ 
Infants and children constitute a large proportion of the population in developing countries. They are especially vulnerable to contract illnesses and to the harmful effects of drugs. Acute respiratory infection, acute watery diarrhoea and viral fever are the common childhood illnesses accounting for the major proportion of pediatric visits. ${ }^{5}$ Most of these are self-limiting and often treated not only inappropriately but also resorting to polypharmacy. ${ }^{6}$ Inappropriate use of antibiotics leads to drug resistance, adverse drug reactions and financial burden to patients. So promotion of appropriate and safe drugs in children is the need of the hour globally. Also most of reported drug utilization studies have been carried out in adult patients with only a few being reported from pediatric patients. ${ }^{7}$

Considering all these facts, current study was designed to assess the prescribing pattern of various drugs in outdoor patients of paediatric department.

\section{METHODS}

This study was a cross sectional study, which was conducted at Maindarkar pediatric hospital, Latur for a period of six months during September 2019 to February 2020 after obtaining permission from the head of the institute. We have analysed total 1000 prescriptions of patients who had visited the OPD of Maindarkar pediatric hospital during that period. Prescriptions were selected by simple random sampling method.

Criteria for inclusion in current study was all pediatric patients from newborn to age less than 12 years of either sex who had visited OPD of the hospital during that period including vaccination. Criteria for exclusion from current study were patients more than 12 years of age and all inpatients.

WHO prescribing indicators and patient indicators (age and sex of the patient) were used to study drug utilization pattern. Following prescribing indicators were used; percentage of drugs/encounter, percentage of antibiotics, percentage of injections, percentage of drugs prescribed from essential drug list and percentage of drugs prescribed by generic name. ${ }^{8}$

Average number of drugs per encounter was calculated by dividing the total number of different drugs prescribed, by the number of encounters surveyed. Percentage of encounters with an antibiotic prescribed and Percentage of encounters with an injection prescribed were calculated by dividing the number of patient encounters during which an antibiotic or an injection are prescribed, by the total number of encounters surveyed, multiplied by 100 . Percentage of drugs prescribed by generic name was calculated by dividing the number of drugs prescribed by generic name by the total number of drugs prescribed, multiplied by 100 . Percentage of drugs prescribed from essential drugs list was calculated by dividing the number of products prescribed which are listed on the essential drugs list by the total number of products prescribed, multiplied by $100 .^{8}$ For analysis of average number of drugs per encounter, combinations were considered as single drug and for the rest of indicators combination were split into individual drugs and counted separately. Indian National list of essential medicines (NLEM) (2015) was used in our study.

\section{Statistical analysis}

Data was entered into Microsoft excel and analyzed. Descriptive statistics such as mean for continuous variables, frequency and percentage for categorical variables were determined.

\section{RESULTS}

A total 1000 prescriptions of paediatric patients who attended OPD of Maindarkar pediatric hospital during September 2019 to February 2020 were analysed.

Most common age group attended OPD during that period was infants (1 month to 1 year) $(55.6 \%)$ followed by neonates $(24.4 \%)$. Only $20 \%$ prescriptions were of children more than 1 year age. Prescriptions of male patients $(54.7 \%)$ were more than female $(45.3 \%)$ patients (Table 1).

Table 1: Age group and gender wise, number of prescriptions.

\begin{tabular}{|llll|}
\hline Age group & $\begin{array}{l}\text { Prescription } \\
\text { for males }\end{array}$ & $\begin{array}{l}\text { Prescription } \\
\text { for females }\end{array}$ & $\%$ \\
\hline $\begin{array}{l}\text { Neonate } \\
\text { (up to 1 } \\
\text { month) }\end{array}$ & 131 & 113 & 24.4 \\
\hline $\begin{array}{l}\text { Infant } \\
\text { (1 month 1 } \\
\text { year) }\end{array}$ & 304 & 252 & 55.6 \\
\hline $\begin{array}{l}\text { Children } \\
\text { >1 year }\end{array}$ & 112 & 88 & 20.0 \\
\hline Total & 547 & 453 & 100 \\
\hline
\end{tabular}

Most common drugs prescribed were non steroidal antiinflammatory drugs $(70.4 \%)$. Drugs used for respiratory disorders $(65.5 \%)$ were the second largest group. It is followed by supplements (60\%). Antimicrobials prescribed $(49.8 \%)$ in nearly half of the prescriptions (Table 2). Penicillins (29.28\%) were most common among antimicrobials prescribed, followed by cephalosporins (27.14\%). macrolides (19.64\%), fluoroquinolones $(11.78 \%)$, antiamoebic drugs $(10.71 \%)$ prescribed less frequently. Antimalarials, doxycycline and chloramphenicol were used least (1.42\%) (Figure 1).

Average number of drugs per prescription was 2.45. Most of the prescriptions had 2 or 3 drugs. Least $(0.4 \%)$ prescriptions had 5 drugs (Table 3). About three forth $(74.41 \%)$ drugs were from national list of essential 
medicines (Table 4). All the drugs were prescribed by brand names. Banned drugs were not prescribed at all. Oral formulations were present in most $(82.5 \%)$ of the prescriptions followed by inhalationals $(20.8 \%)$ including nebulization followed by injectables including vaccines (15\%) (Figure 2).

Table 2: Frequency of prescribing drugs.

\begin{tabular}{|lll|}
\hline Drugs & $\begin{array}{l}\text { Number of } \\
\text { prescriptions }\end{array}$ & $(\%)$ \\
\hline Antimicrobials & 498 & 49.8 \\
\hline NSAIDS & 704 & 70.4 \\
\hline Respiratory drugs & 655 & 65.5 \\
\hline GIT drugs & 440 & 44 \\
\hline Supplements & 600 & 60 \\
\hline CNS drugs & 54 & 5.4 \\
\hline CVS drugs & 23 & 2.3 \\
\hline $\begin{array}{l}\text { Other drugs (vaccines, } \\
\text { steroids) }\end{array}$ & 160 & 16 \\
\hline
\end{tabular}

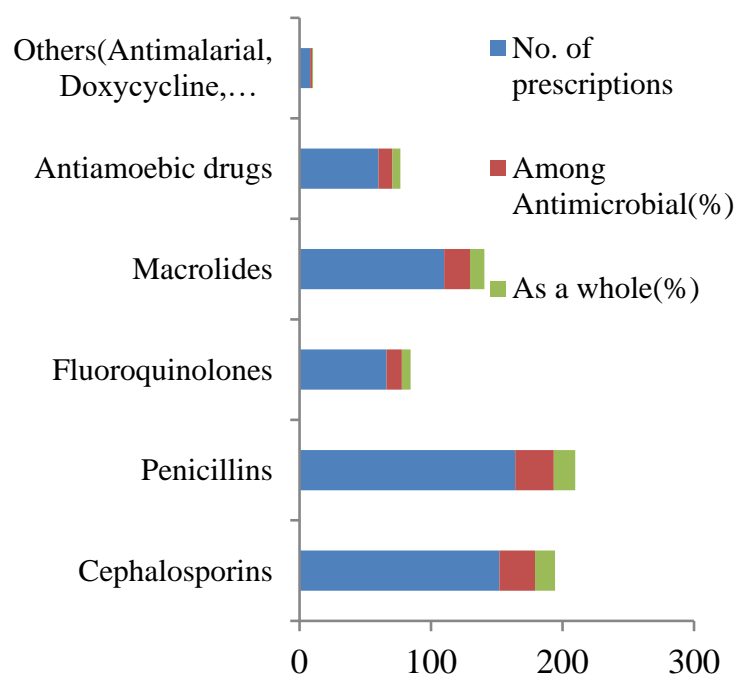

Figure 1: Prescribing prevalence of antimicrobials.

Table 3: Number of drugs per prescription.

\begin{tabular}{|lll|}
\hline $\begin{array}{l}\text { No. of drugs per } \\
\text { prescription }\end{array}$ & $\begin{array}{l}\text { Prescription } \\
\text { N }(\%)\end{array}$ & $\begin{array}{l}\text { Total number } \\
\text { of drugs }\end{array}$ \\
\hline $\mathbf{1}$ & $132(13.2)$ & 132 \\
\hline $\mathbf{2}$ & $382(38.2)$ & 764 \\
\hline $\mathbf{3}$ & $393(39.3)$ & 1179 \\
\hline $\mathbf{4}$ & $89(8.9)$ & 356 \\
\hline $\mathbf{5}$ & $4(0.4)$ & 20 \\
\hline Total & $1000(100)$ & 2451 \\
\hline
\end{tabular}

Table 4: Drugs from NLEM.

\begin{tabular}{|ll}
\hline Drug utilization parameter & N (\%) \\
\hline Drug from NLEM & $1824(74.41)$ \\
\hline
\end{tabular}

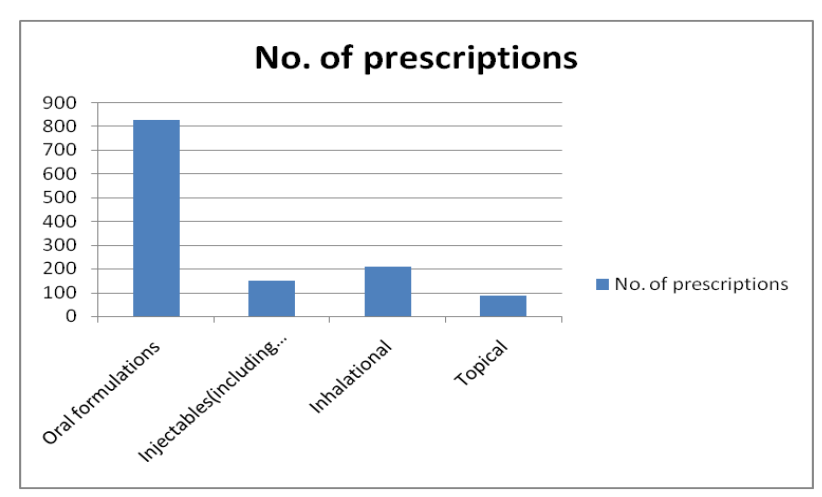

Figure 2: Use of different formulations for drug administration.

\section{DISCUSSION}

Drug utilization studies are essential part of pharmacoepidemiological studies which provide a proper understanding of usage pattern of drugs, quality and efficiency of drug use and its outcomes. ${ }^{9}$ Such types of studies can play a key role in helping the healthcare system to understand, interpret and improve the prescribing, administration and to maintain the rational use of drugs. ${ }^{10}$

In our study, we included 1000 prescriptions of OPD randomly collected over six months duration from September 2019 to February 2020. Infants (1 month to 1 year) $(55.6 \%)$ visited OPD more than neonates $(24.4 \%)$ and children $>1$ year $(20 \%)$. This indicates maximum patients were from age group of 1-12 months. This is in accordance with finding of Najmi et al, where $48 \%$ patients were infants. ${ }^{11}$ In present study, male patients $(54.7 \%)$ were more as compared to female patients $(45.3 \%)$. It reflects a deep rooted gender bias in the Indian society.

In India, the most common disease affecting children is acute respiratory infection (ARI), which is responsible for about $30-50 \%$ of visits to health facilities and for about $20-40 \%$ hospital admissions. ${ }^{12}$ Similarly in our study after nonsteroidal anti-inflammatory drugs (NSAIDs) (70.4\%), most commonly prescribed drugs were for respiratory disorders $(65.5 \%)$. Paracetamol, mefenamic acid, ibuprofen were commonly used NSAIDs. Whereas cetirizine, phenylephrine, chlorpheniramine, salbutamol, montelukast, cough syrups were used for respiratory disorders. Similarly, a study on outpatient pediatric patients from India indicated paracetamol as the most frequently prescribed drug. ${ }^{13}$ In present study, supplements $(60 \%)$ include multivitamins, hematinics, calcium, zinc, amino acids, cerelac, milk formulae. antimicrobials $(49.8 \%)$ were prescribed less frequently.

Above groups were followed by prescriptions for gastrointestinal system $(44 \%)$. It includes ORS, domperidone, lactulose, dicyclomine, probiotics etc. Vaccines and steroids were found in $16 \%$ prescriptions. 
Vaccines include routine and optional vaccination where as steroid were mostly used topically for dermatological conditions. In our study we found that prescriptions for CNS and CVS systems were very less (5.4\% and $2.3 \%$ respectively), it indicates that these patients were mostly admitted and treated only after examination, investigations under observation. Digoxin, spironolactone, enalapril and furosemide from cvs where as sodium valproate, levetiracetam, clobazam, phenobarbitone, lamotrigine and piracetam from CNS were commonly used drugs in present study.

We found that penicillins were most commonly prescribed antimicrobials (29.28\%) followed by cephalosporins $(27.14 \%)$. Amoxicillin, clavulanic acid, cefixime, cefpodoxime, cefdinir, cefprozil, cefaclor, cefadroxil are commonly used beta lactams. Among macrolides (19.64\%) azithromycin, clarithromycin, roxithromycin; among fluoroquinolones (11.78\%) ciprofloxacin, norfloxacin and among antiamoebic $(10.71 \%)$ metronidazole, secnidazole, ornidazole were commonly used drugs. Antimalarials, doxycycline and chloramphenicol were found in least $(1.42 \%)$ number of prescriptions. In other study among antimicrobials, penicillins $(28.75 \%)$ were most commonly prescribed, followed by aminoglycosides (23.33\%) and cephalosporins $(17.5 \%){ }^{14}$

Prescribing minimum required number of drugs per patient carries less chances of drug-drug interactions and adverse effects of drugs, decreased cost of therapy and increased patient's compliance. In this study, number of drugs prescribed in any patient ranged from 1 to 5 with an average of 2.45 drugs per patient. Which is less as compared to $(3.7 \pm 0.1)$ study done by Nazima et al. ${ }^{15}$ In other studies, average number of drugs per encounter were 5.69 (inpatients), 5.61 (outpatients+inpatients), 2.7 (outpatients+inpatients), 2.35 (outpatients). ${ }^{14,16-18}$

About three fourth $(74.41 \%)$ prescribed drugs were from NLEM. Paracetamol, amoxicillin, cetirizine, chlorpheniramine, salbutamol, albendazole and antacid preparations containing aluminium and magnesium hydroxide contributed to the majority of drugs prescribed from the NLEM. Which was higher as compared to study by Thiruthopu where about half of the drugs (49.78\%) prescribed were from EDL, it was lower as compared to study by Nazima et al where $77.6 \%$ drugs rated essential. ${ }^{15,19}$

All the drugs in present study were prescribed by brand names. Which is in accordance with the study by Dimri et al where only $5.8 \%$ drugs prescribed by generic name. ${ }^{13}$ Also a study by Sankhla et al, only $13.09 \%$ drugs were prescribed by generic names. ${ }^{20}$ One of the reasons for poor prescribing by generic name is the non-availability of the pediatric formulations in the hospital pharmacy. Hence, clinicians often prefer to prescribe by trade names, with which they are familiar and the patients find it easier to procure. None of them is banned drug.
Prescribing medicines by official names avoids the confusion and makes the drug therapy rational and cheaper.

In the present study, oral formulations are widely used $(82.5 \%)$ followed by inhalational $(20.8 \%)$ including nebulization followed by injectables (15\%) including vaccines. Comparable finding is seen in another study by Balushi et al where the most common route of drug administration was the oral route $(59 \%)$ followed by injection and inhalation (15\% and $13 \%$, respectively). ${ }^{21} \mathrm{In}$ our study topical formulations $(8 \%)$ used least. It includes topical steroids and NSAIDs.

There are some limitations of our study. The study was carried out over a period of 6 months. Seasonal variations in disease pattern and drug utilization were not considered. The study included only outdoor patients. The drug cost was not taken into account. The study was restricted to only one hospital.

\section{CONCLUSION}

From current study it can be concluded that most common prescriptions were of infants of male gender. Commonly prescribed drugs were NSAIDS (70.4\%) followed by drugs for respiratory disorders $(65.5 \%)$ and supplements $(60 \%)$. Antimicrobials were present in about half $(49.8 \%)$ of the prescription. Most common antimicrobial prescribed was penicillin (29.28\%). Average number of drugs per prescription was 2.45. Oral route $(82.5 \%)$ was preferred over parenteral for drug administration. Majority of the prescribed drugs (74.41\%) were from national list of essential medicines. All drugs were prescribed by brand names. None of the prescription contained banned drug. Such drug utilization studies are necessary to improve prescribing, administration, to minimize adverse events and promote rational use of medicines.

\section{ACKNOWLEDGEMENTS}

Authors of the current study are thankful to Dr. Kavita Maindarkar for constant support and guidance for the successful completion of the study. Also we are thankful to medical staff for their cooperation during the study.

Funding: No funding sources

Conflict of interest: None declared

Ethical approval: The study was approved by the Institutional Ethics Committee

\section{REFERENCES}

1. World health organization, the selection of essential drugs, technical report series no. 615. Available at: https://apps.who.int/iris/handle/10665/41272.

Accessed on 25 August 2020.

2. World health organisation, rational use of medicines. Available at: http://www.who.int/medicines/areas/ 
rational_use/en/index.html; 2010. Accessed on 25 August 2020.

3. Bhatt JH, Verma S, Bagde S, Sane RM, Shahani S. Drug utilization study in ophthalmology in OPD patients at a tertiary care teaching hospital. Int $\mathbf{J}$ Basic Clin Pharmacol. 2018;7:315-8.

4. Chandra S, Khan IN, Mateenudin M, Chandrakapure A, Maaz S, Mubin F. Drug utilization study in OPD of a tertiary care hospital in a rural area of Jalna, Maharashtra, India by using WHO prescribing indicators. Int J Basic Clin Pharmacol. 2018;7:55-8.

5. Bharathiraja R, Sridharan S, Chelliah LR, Suresh S, Senguttuvan M. Factors affecting antibiotic prescribing pattern in paediatric practice. Indian $\mathbf{J}$ Paediatric. 2005;72:877-80.

6. Gupta A, Maheshwari P, Dokania KK, Tambe JJ. Drug utilization pattern in sick paediatric patients: analysis for rationality and other aspects. Int $\mathrm{J}$ Basic Clin Pharmacol. 2017;6:2815-21.

7. Chavda DA, Mistry RA, Solanki KC, Suthar SD, Desai BL, Mistry SD. Drug utilization study in the inpatients of paediatric department of a tertiary care hospital. Int J Basic Clin Pharmacol. 2015;4:729-33.

8. WHO, how to investigate drug use in health facilities EMD Research. Available at: https://www.who.int/ medicines/publications/how-to-investigate_druguse/en/. Accessed on 25 August 2020.

9. Shimpi RD, Salunkhe PS, Bavaskar SR, Laddha GP, Kalam A, Patel KA. Drug utilization evaluation and prescription monitoring in asthmatic patients. Int $\mathrm{J}$ Pharm Bio Sci. 2012;2(1):117-22.

10. Avula N, Sravani MR. Study of drug utilization trends in respiratory tract infections in a tertiary care teaching hospital: a retrospective study. Int $\mathrm{J}$ Basic Clin Pharmacol. 2017;6:2583-6.

11. Nazmi A, Verma A, Aiman U. Drug utilization study in the outpatient pediatric department of a tertiary care teaching hospital of district Lucknow. Asian J pharm Clin Res. 2015;8(3):327-30.

12. Bukhari S, Gaash B, Ahmad M, Farheen A. Household survey of childhood morbidity and parental practices in Budgam district. Indian $\mathbf{J}$ Pract Dr. 2008;4(6):1-5.
13. Dimri S, Tiwari P, Basu S, Parmar VR. Drug use pattern in children at a teaching hospital. Indian Pediatr. 2009;46:165-7.

14. Vishwanath M, Reddy NS, Devadas S. Assessment of drug utilization in hospitalized children at a tertiary care teaching hospital. J Chem Pharm Res. 2014;6(2):592-8.

15. Nazima YM, Sagun D, Barna G. Prescribing pattern in a pediatric out-patient department in Gujarat. Bangladesh J Pharmacol. 2009;4:39-42.

16. Akhtar MS, Vohara D, Pillai KK. Drug prescribing practices in pediatric department of a North Indian University Teaching Hospital. Asian J Pharm Clin Res. 2012;5(1):146-9.

17. Suman RK, Mohanty NC, Mohanty IR. The study of drug usage patterns in pediatric patients at MGM Hospital, Navi Mumbai. World J Pharm Res. 2014;3 (4):734-43.

18. Sachdeo G, Keche Y, Yegnanarayan R. Prescription analysis of drugs prescribed for children in some town of Maharashtra. Asian J Biomed Pharm Sci. 2013;3(21):17-9.

19. Thiruthopu NS, Mateti UV, Bairi R, Sivva D, Martha S. Drug utilization pattern in South Indian pediatric population: A prospective study. Perspect Clin Res. 2014;5:178-83.

20. Sankhla S, Gaur S. A retrospective study of drug utilization pattern in the outpatient department of pediatrics in a tertiary care teaching hospital of Rajasthan, India. Int J Basic Clin Pharmacol. 2016; 5:2025-31.

21. Al-Balushi KA, Al-Sawafi F, Al-Ghafri F, AlZakwani I. Drug utilization pattern in an Omani pediatric population. J Basic Clin Pharma. 2013;4: 68-72.

Cite this article as: Parekar SM, Maindarkar GK, Maindarkar VV. Drug utilization pattern in outdoor patients of pediatric tertiary care hospital: a cross sectional study. Int J Basic Clin Pharmacol 2020;9:1725-9. 